\title{
HERNÁNDEZ GUERRA, Liborio, La mujer liberta en la sociedad his- pano-romana durante el imperio, Salamanca, Ediciones Universi- dad, 2018, 225 págs., ISBN: 978-84-9012-952-4.
}

\author{
Ricardo MARTÍNEZ LACY \\ https://orcid.org/0000-0002-1672-4156 \\ Universidad Nacional Autónoma de México, México \\ lacy@unam.mx
}

PALABRAS ClaVE: libertas, mujeres, Hispania

KEYWORDS: Freedwomen, Women, Hispania

RECIBIDO: 07/01/2020 • ACEPTADO: 10/01/2020 • VERSIÓN FINAL: 12/01/2020

Esta obra apareció en la colección Memoria de mujer. Se trata de una monografía de pretensiones enciclopédicas basada sobre todo en inscripciones y algunos textos. La mayoría de las inscripciones son epitafios y exvotos, hubiera convenido que el autor diera una explicación de la naturaleza y características de dichos textos. También hubiera sido bueno que explicara la representatividad de ellos, pues es claro que sólo las personas más ricas mandaban a erigir inscripciones y, en consecuencia, éstos son testimonio de ascenso social desde los estratos más bajos de la sociedad. Por las citas que inserta Hernández, parece que las inscripciones alcanzan las centenas y el autor las maneja magistralmente.

El libro está dividido en una introducción, cuatro capítulos y conclusiones. El primer capítulo se intitula "El origen de las libertas hispanas" (pp. 17-97), el segundo, "Promoción social y movilidad de las libertas" (pp. 98-138), el tercero, "El mundo laboral de la mujer liberta" (pp. 139-160) y el cuarto, "Las creencias religiosas de las libertas" (pp. 161-182). El libro trata el tema exhaustivamente, pero se echa de menos algunos planteamientos generales como las diferencias entre las libertas, las esclavas y las mujeres libres, o las diferencias entre las libertas y los libertos o una comparación entre las libertas de Hispania y las del resto del Imperio romano. El autor tampoco explica por qué abarca sólo la época imperial y no la republicana. Contiene unos índices de corpora, repertorios y revista, otro de fuentes librescas, un índice onomás- 
tico y otro geográfico. Falta un índice de inscripciones, que hubiera sido muy útil. Un lector no hispano extraña que los nombres de los lugares se den sólo en latín y supongo que se consignan en español cuando no se conoce el nombre original, aunque eso no se diga en ninguna parte.

Cada capítulo abarca todo lo que las fuentes permiten. En el primero se habla de documentos de manumisión, del origen y los desplazamientos de las libertas, de su situación conyugal, de las muertes tempranas, de los derechos de libertas y finalmente de sus nombres.

El capítulo segundo presenta algunos ejemplos de movilidad social y trata las relaciones familiares, en qué ciudades vivían, características de las libertas públicas, las mujeres de los augustales, que eran sacerdotes del culto a los emperadores muertos, su participación en asociaciones y sus beneficios públicos.

En el capítulo tercero se habla sobre los oficios de las libertas: la agricultura y ganadería, la minería, la industria, el arte, el cuidado de los demás y, finalmente, las profesiones liberales.

La religiosidad de las libertas expone según qué cultos ejercían, los cultos romanos tradicionales, los de los emperadores, los de dioses orientales, entre los que no se encuentran cultos judíos ni cristianos, y cultos locales hispanos.

Aunque no soy especialista, tengo la impresión de que éste es el mejor libro que se ha escrito sobre el tema.

$$
* * *
$$

RicaRdo MARTínez LACY es doctor por la Universidad de Cambridge e investigador del Instituto de Investigaciones Filológicas, de la Universidad Nacional Autónoma de México. Se desempeña como profesor de asignatura de la Facultad de Filosofía y Letras. Su línea de investigación es la historiografía antigua y moderna. Sus publicaciones más recientes son el libro ¿En busca del tiempo perdido? Ensayos sobre historia antigua y el artículo "Interpretación de algunos tratados relacionados con las dos primeras guerras macedónicas", Interpretatio, 4-2, septiembre de 2019-febrero de 2020 . 